\title{
THE CONCEPTS OF OFFICE WORK AND ARCHIVING IN TERMINOLOGICAL STANDARDS: A COMPARATIVE ASPECT
}

\author{
Alina I. Topaz \\ Volgograd State University, Volgograd, Russia
}

\begin{abstract}
In the article, in order to identify the dynamics of the conceptual apparatus of the subject area of records management and archival business, a comparative analysis of standards for terms and definitions of GOST R 51141-98 and GOST R 7.0.8-2013 is carried out. The standard is characterized as a type of document that fixes special concepts, as an important lexicographic source that contributes to the unification and normalization of terminology. The properties of conventionality and definitiveness of terminological units, which are important for the process of standardization and determine the features of the term as a language sign and affect its unambiguous interpretation by specialists, are considered. The similarities and differences in the structure of the standards under consideration, in the body of special tokens that are used in professional communication in the field of records management and archival business are revealed. The comparison of the GOST R 7.0.8-2013 with the previous document resulted in distinguishing several groups of terminological units with regard to their semantics, which is expressed in definitions, and significance in the modern system of concept record management and archival affairs: the terms, which are not included in the standard as obsolete; the terms, which preserved the former meaning; the terms with altered meaning; new terms, the appearance of which is associated with the development of the professional sector. The factors that determine the dynamics of the term system of records management and archival business are established.
\end{abstract}

Key words: paperwork, archiving, document, terminological standard, standardization, term, definition, lexicography.

Citation. Topaz A.I. The Concepts of Office Work and Archiving in Terminological Standards: A Comparative Aspect. Vestnik Volgogradskogo gosudarstvennogo universiteta. Seriya 2. Yazykoznanie [Science Journal of Volgograd State University. Linguistics], 2019, vol. 18, no. 3, pp. 217-226. (in Russian). DOI: https://doi.org/ 10.15688/jvolsu2.2019.3.18

УДК 81’374:651

ББК 81.054
Дата поступления статьи: 30.04.2019 Дата принятия статьи: 26.08.2019

\section{ПОНЯТИЯ ДЕЛОПРОИЗВОДСТВА И АРХИВНОГО ДЕЛА В ТЕРМИНОЛОГИЧЕСКИХ СТАНДАРТАХ: СОПОСТАВИТЕЛЬНЫЙ АСПЕКТ}

\author{
Алина Игоревна Топаз \\ Волгоградский государственный университет, г. Волгоград, Россия
}

Аннотация. В статье с целью выявления динамики понятийного аппарата предметной области делопроизводства и архивного дела проведен сопоставительный анализ стандартов на термины и определения ГОСТ Р 51141-98 и ГОСТ Р 7.0.8-2013. Стандарт охарактеризован как вид документа, фиксирующий специальные понятия, и как лексикографический источник, способствующий унификации и нормированию терминологии. Рассмотрены важные для процесса стандартизации свойства конвенциональности и дефинитивности терминологических единиц, обусловливающие особенности термина как языкового знака и 


\section{МАТЕРИАЛЫ И СООБЩЕНИЯ}

влияющие на его однозначную трактовку специалистами. Выявлены сходства и различия в структуре анализируемых стандартов, в корпусе специальных лексем, которые используются в профессиональной коммуникации сферы делопроизводства и архивного дела. На основе сравнения терминологических стандартов выделены группы терминологических единиц с учетом их семантики, формой выражения которой служит дефиниция, и значимости в современной системе понятий делопроизводства и архивного дела: термины, не включенные в стандарт как вышедшие из употребления; термины, сохранившее прежнее значение; термины, значение которых изменилось; новые термины, появление которых связано с развитием профессиональной отрасли. Установлены факторы, обусловливающие динамику терминосистемы делопроизводства и архивного дела.

Ключевые слова: делопроизводство, архивное дело, документ, терминологический стандарт, стандартизация, термин, дефиниция, лексикография.

Цитирование. Топаз А. И. Понятия делопроизводства и архивного дела в терминологических стандартах: сопоставительный аспект // Вестник Волгоградского государственного университета. Серия 2, Языкознание. - 2019. - Т. 18, № 3. - С. 217-226. - DOI: https://doi.org/10.15688/jvolsu2.2019.3.18

\section{Введение}

Архивы играют важную роль в формировании современного информационного социума, обеспечивая сохранение историко-культурного наследия государства. Предоставляя доступ к ретроспективной информации, они содействуют, как отмечает Л.С. Кузнецов, решению задач социально-экономического, политического, образовательного, воспитательного и культурного характера, способствуют развитию гражданского общества и эффективному государственному управлению [Кузнецов, 2010].

Современная государственная политика в сфере архивного дела направлена на совершенствование предоставления информационных услуг пользователям - государственным органам, органам местного самоуправления, юридическим и физическим лицам. Реализация данной политики обусловливает изменение правовой и научно-методической базы архивного дела, регламентацию исполнения архивных услуг, обеспечивает безопасность хранения документов, большую доступность архивных информационных услуг [Топаз, 2017]. В этом процессе важная роль отводится стандартизации деятельности, направленной на разработку и установление характеристик какого-либо объекта, правил, упорядочивающих осуществление процесса (ГОСТ 1.1-2002). Предлагаемые характеристики и правила находят воплощение в стандарте как особом виде регламентирующего документа.

Эффективность производственных процессов во многом обусловливается однознач- ным пониманием и правильным использованием терминов, отражающих понятия соответствующей предметной области, что требует стандартизации понятийно-терминологического аппарата и его фиксацию в лексикографических источниках - стандартах на термины и определения, или терминологических стандартах.

Стандарт как регулирующий документ обеспечивает успешность деловой коммуникации, однако развитие практической деятельности, в частности внедрение новых технологий, модернизация процессов, связанная с информатизацией и др., приводит к несоответствию содержания терминов, используемых в практической деятельности специалистов, и терминов, отраженных в терминологически стандартах. В связи с этим возникает необходимость корректировки стандарта, упорядочения содержащихся в нем терминов.

Так, за последние 20 лет в сфере делопроизводства и архивного дела отмечается немало позитивных процессов, в частности появились новые исследования, связанные с изучением документных систем, результаты которых позволили ввести в делопроизводственную практику более совершенные технологии, поновому организовать процессы создания и обработки документов на всех этапах их жизненного цикла, включая передачу на архивное хранение, на новом уровне. Эти процессы определили изменение понятийно-терминологического аппарата архивоведения и появление в 2013 г. нового терминологического стандарта, который заменил стандарт 1998 года. 
Сопоставление разных в хронологическом отношении стандартов позволяет выявить динамику терминосистемы сферы делопроизводства и архивного дела, факторы, которые ее детерминируют, и представить направления и способы совершенствования деловой коммуникации в соответствующей профессиональной сфере.

\section{Терминологический стандарт как лексикографический нормативный источник}

Действующее российское законодательство определяет стандарт как документ, в котором в целях добровольного многократного использования устанавливаются характеристики продукции, правила осуществления и характеристики процессов проектирования (включая изыскания), производства, строительства, монтажа, наладки, эксплуатации, хранения, перевозки, реализации и утилизации, выполнения работ или оказания услуг (Федеральный закон № 125-Ф3). Стандарт также может содержать правила и методы исследований (испытаний) и измерений, правила отбора образцов, требования к терминологии, символике, упаковке, маркировке или этикеткам и правилам их нанесения.

Система стандартов была разработана и внедрена в практику еще в СССР. С 1992 г. государственный стандарт Российской Федерации имеет обозначение ГОСТ Р. Он подтверждает, что продукция прошла проверку и отвечает всем требованиям безопасности. В 2003 г. государственные стандарты, которые были приняты Госстандартом России до 1 июля 2003 г., признаны национальными.

С помощью стандартов осуществляется процесс унификации формы документов, в определенной степени единообразно структурируется их содержания, что делает удобной работу с ними. В этом отношении стандарт служит «типовым документом», образцом, которому должны соответствовать «конкретные» документы того или иного вида. Оформление документа в соответствии с требованиями стандарта придает ему юридическую силу, а область действия стандартов и их содержание определяются государственными органами управления. Государственные стандарты в со- ответствии с законом «О стандартизации» (Федеральный закон № 162-Ф3) принимает Госстандарт.

Терминологический стандарт представляет собой контролируемый профессиональным сообществом словарь специальных единиц, в котором раскрывается их содержание и дается оценка с точки зрения нормы.

Терминологические стандарты создаются для единообразного понимания терминов и для достижения следующих целей:

- ускорения процессов коммуникации и обмена информацией;

- нормативного закрепления содержания терминов, что обеспечивает их использование на практике в рамках единого подхода;

- устранения коммуникативных барьеров в профессиональном общении;

- языковой репрезентации современной научной информации;

- унификации терминологии, то есть приведения терминов к единообразию на содержательном, логическом и лингвистическом уровнях с учетом общих норм и закономерностей языка, что обеспечивает однозначное соответствие между системой понятий и терминосистемой.

Кроме того, как отмечает В.Ф. Янковая, стандарты, «будучи инструментом организации и координации терминологической подсистемы определенной предметной области знаний, могут выполнять роль методического справочника по терминологии на этапе создания полноценной терминосистемы той или иной области знания» [Янковая, 2014, с. 22-23].

Стандартизованные термины обязательны для применения во всех видах документации и специальной литературы в конкретной отрасли. Каждый ГОСТ содержит термины с их краткими вариантами, а также недопустимыми синонимами (с пометами «Ндп», «Нрк»), дефиниции понятий, называемых терминами, и эквиваленты. Для оформления используются разные шрифты: стандартизуемый термин выделяется полужирным шрифтом, недопустимый или нерекомендуемый курсивом. Однако эти обязательные компоненты стандарта допускают некоторую вариативность, встраиваясь в общую, целостную композиционно-содержательную структуру документа. 


\section{Структура стандартов на термины и определения сферы делопроизводства \\ и архивного дела}

Обратимся к двум стандартам, которые содержат термины, используемые в сфере делопроизводства и архивного дела, и их определения: ГОСТ Р 51141-98 «Делопроизводство и архивное дело. Термины и определения» и введенный взамен его ГОСТ Р 7.0.8-2013 «СИБИД. Делопроизводство и архивное дело. Термины и определения».

Документы различаются количеством содержащихся в них единиц. ГОСТ Р 51141-98 включает 125 терминов, ГОСТ Р 7.0.8-2013 174 термина, что отражает качественные изменения, происшедшие в терминосистеме с 1998 по 2013 год.

Структура документов имеет общие черты. В частности, их текст делится на 3 основных раздела: «Общие понятия», «Делопроизводство» и «Архивное дело», внутри которых выделяются подразделы, отражающие содержательные части предметных областей (см. таблицу).

Сравнение показывает, что термины в рассматриваемых стандартах распределены по разделам неодинаково. В ГОСТ Р 51141-98 раздел «Архивное дело» имеет три подраздела, связанные с организацией работы архива: «Организация документов Архивного фонда Российской Федерации», «Обеспечение сохран- ности документов», «Научно-информационная деятельность архивов»; в ГОСТ Р 7.0.8-2013три подраздела, отражающие направления деятельности архива: «Хранение и учет архивных документов», «Комплектование архива», «Информационная деятельность архива». Как показывает практика, структурирование содержания по направлениям деятельности архивов обеспечивает более быстрый поиск в документе необходимой информации.

По-разному осуществлена и систематизация терминов. Одни и те же терминологические единицы включены в стандартах в разные разделы. Например, термины архив, архивный документ, экспертиза иенности документов в ГОСТ Р 51141-98 находятся в подразделе «Организация документов Архивного фонда Российской Федерации» раздела «Архивное дело», а в ГОСТ Р 7.0.8-2013 - в разделе «Общие понятия». В ГОСТ Р 5114198 термин постоянное хранение документов входит в подраздел «Обеспечение сохранности документов» раздела «Архивное дело», а в ГОСТ Р 7.0.8-2013 - в раздел «Общие понятия».

Сходство стандартов ГОСТ Р 51141-98 и ГОСТ Р 7.0.8-2013 обнаруживается в одинаковом графическом оформлении терминов: стандартизированные термины набраны полужирным шрифтом, их краткие формы (аббревиатуры) даны без выделения, синонимы маркированы курсивом, например:

\section{Структура стандартов на термины}

\begin{tabular}{|c|c|}
\hline ГОСТ Р 51141-98 & ГОСТ Р 7.0.8-2013 \\
\hline Предисловие & Предисловие \\
\hline Введение & Введение \\
\hline 1. Область применения & 1. Область применения \\
\hline- & 2. Нормативные ссылки \\
\hline $\begin{array}{l}\text { 2. Стандартизованные термины с определе- } \\
\text { ниями }\end{array}$ & 3. Термины и определения \\
\hline 2.1. Общие понятия & 3.1. Общие понятия \\
\hline 2.2. Делопроизводство & 3.2. Делопроизводство \\
\hline 2.2.1. Документирование & 3.2.1. Документирование \\
\hline 2.2.2. Организация работы с документами & 3.2.2. Организация работы с документами \\
\hline 2.3. Архивное дело & 3.3. Архивное дело \\
\hline $\begin{array}{l}\text { 2.3.1. Организация документов Архивно- } \\
\text { го фонда Российской Федерации }\end{array}$ & 3.3.1. Хранение и учет архивных документов \\
\hline 2.3.2. Обеспечение сохранности документов & 3.3.2. Комплектование архива \\
\hline $\begin{array}{l}\text { 2.3.3. Научно-информационная деятель- } \\
\text { ность архивов }\end{array}$ & 3.3.3. Информационная деятельность архива \\
\hline $\begin{array}{l}\text { Алфавитный указатель терминов на русском } \\
\text { языке }\end{array}$ & Алфавитный указатель терминов \\
\hline
\end{tabular}


научно-справочный аппарат архива, справочно-поисковые средства архива; НСА архива: Совокупность описаний архивных документов.

В обоих ГОСТ ряд терминов содержит части, заключенные в круглые скобки, например: документационное обеспечение (уnравления), ДОУ. При использовании термина в документах часть, заключенная в скобки, может быть опущена.

Недопустимые или нерекомендуемые к применению термины-синонимы приведены в круглых скобках после стандартизированного термина и обозначены пометами «Нрк» или «Ндп». Термины-синонимы без пометы приведены в качестве справочных, например:

архив (Нрк архивохранилище): Организация или структурное подразделение организации, осуществляющее комплектование, учет, хранение и использование архивных документов.

\section{Динамика терминологической системы делопроизводства и архивного дела}

В процессе стандартизации терминологии, подготовки ее для отражения в терминологическом стандарте необходимо учитывать свойства термина как языкового знака [Янковая, 2014].

В.Ф. Янковая отмечает, что «термин представляет собой единицу языка (слово, словосочетание, аббревиатура, символ, сочетание слова и символов в виде букв или цифр), которая является наименованием специального понятия какой-либо сферы научной или профессиональной деятельности и употребляется в особых условиях» [Янковая, 2014]. Термины обладают рядом отличительных свойств, однако для представления их в терминологическом стандарте релевантны прежде всего конвенциональность и дефинитивность.

В широком смысле конвенцииональность означает, по мнению С.В. Гринева-Гриневича, «договоренность относительно содержания термина, целенаправленный характер его появления, то есть сознательное терминотворчество» [Гринев-Гриневич, 2008, с. 29]. А.В. Лемов понимает конвенциональность термина как соглашение по меньшей мере нескольких специалистов принять предложенную одним из них форму выражения нового тер- мина и применять ее к определенному создателем термина содержанию [Лемов, 2000, с. 85-86]. Конвенциональность термина допускает некоторую свободу в его использовании, дает возможность выразить авторский взгляд на то или иное явление, что обычно происходит в сфере науки и способствует научному поиску; в то же время конвенциональность становится одной из причин многозначности в терминологии, что затрудняет практическую профессиональную коммуникацию.

С конвенциональностью связано свойство дефинитивности - наличие у термина дефиниции, которая раскрывает содержание обозначенного им понятия. В.В. Белый рассматривает дефиницию термина как важнейшее связующее звено в соотношении «термин - понятие», необходимую составляющую специального лексического значения термина, которое приписывается ему в результате коллективной договоренности [Белый, 1982, c. 23]. В научной литературе отмечается, что дефиниция термина дает общее представление об именуемом объекте, одновременно устраняя возможную неоднозначность, свойственную одноименному слову общего языка. Она должна быть соизмеримой с тем, что она определяет, не должна содержать порочного круга и -быть негативной там, где возможно позитивное определение [Янковая, 2014].

Дефиниция должна с необходимой степенью достоверности отразить главные информационные характеристики предмета, то есть однозначно указать на него, обнаружить среди других предметов и выделить его системные особенности. Дефиниция позволяет определить сущность термина для дальнейшего его употребления в той или иной сфере деятельности. В терминологическом стандарте дефиниция закрепляет значение термина, отражая совокупность признаков, необходимых и достаточных для выделения его среди других терминов.

Что касается терминов и раскрывающих их значение дефиниций, то в сравниваемых нами стандартах обнаруживаются как сходства, так и различия.

Дефиниция термина раскрывает содержание понятия. Однако научные понятия не являются статичными: познание объекта исследования меняет их содержание и объем, 


\section{МАТЕРИАЛЫ И СООБЩЕНИЯ}

что должно найти отражение в дефиниции термина [Касавин, 2009].

Научные знания системны, и это получает отражение в системе терминов, или терминосистеме, - совокупности терминологических единиц, связанных определенными отношениями (род - вид, часть - целое, сходство - противоположность и др.). В лингвистике, и в частности терминоведении как одном из частных лингвистических направлений, принято разграничивать понятия «терминология» и «терминосистема». При этом терминологией называют не совсем упорядоченную совокупность терминов, характерную для формирующихся наук, а терминосистемой - хорошо организованную, «строгую» систему единиц, которая, возможно, подверглась сознательному вмешательству специалистов, осуществивших унификацию и стандартизацию терминологических единиц.

Система языка, и в частности любая терминологическая система как ее часть, постоянно находится в динамике. Это важно учитывать при проведении лингвистического анализа. Так, рассматривая терминологию стандарта, мы используем понятия «хронологическая динамика» (изменение терминов и терминосистемы в целом во времени, что проявляется при сопоставлении разных в хронологическом отношении стандартов) и «синхроническая динамика» (нестатичное состояние терминосистемы на уровне одного синхронного среза, проявляющееся в вариативности форм и содержания единиц, что обнаруживается в тексте одного стандарта).

Анализ ГОСТ Р 7.0.8-2013 и сравнение его с предшествующим позволил выделить следующие группы терминов:

1. Термины, не включенные в ГОСТ Р 7.0.8-2013 как вышедшие из употребления.

Например,

документ на машинном носителе: Документ, созданный с использованием носителей и способов записи, обеспечивающих обработку его информации электронно-вычислительной машиной (ГОСТ Р 51141-98);

машинописный документ: Письменный документ, при создании которого знаки письма наносят техническими средствами (ГОСТ Р 51141-98);

рукописный документ: Письменный документ, при создании которого знаки письма наносят от руки (ГОСТ Р 51141-98) - не вошли в ГОСТ Р 7.0.8-2013, так как утратили свою практическую значимость.

\section{2. Термины, содержание и дефиниция которых не изменились.}

Например:

дело: Документ или совокупность документов, относящихся к одному вопросу или участку деятельности, помещенных в отдельную обложку (ГОСТ P 7.0.8-2013);

фондообразователь: Юридическое или физическое лицо, в процессе деятельности которого образуется документальный фонд (ГОСТ Р 7.0.8-2013).

$\mathrm{Cp}$.:

дело: Совокупность документов или документ, относящихся к одному вопросу или участку деятельности, помещенных в отдельную обложку (ГОСТ Р 51141-98);

фондообразователь: Юридическое или физическое лицо, в деятельности которого образуется документальный фонд (ГОСТ Р 51141-98).

\section{3. Термины, содержание и дефиниция которых изменились.}

В этой группе отмечено несколько терминов, обозначающих базовые понятия документоведения и архивного дела. Изменение их семантики связано с расширением содержания и объема понятия, включением в него дополнительных признаков. Например:

архивное дело: Отрасль деятельности, обеспечивающая организацию хранения и использования архивных документов (ГОСТ Р 51141-98);

архивное дело: Деятельность, обеспечивающая организацию хранения, комплектования, учета и использования архивных документов (ГОСТ P 7.0.8-2013);

постоянное хранение документов: Бессрочное хранение документов в архивном учреждении, государственном музее, библиотеке (ГОСТ Р 51141-98);

постоянное хранение документов: Вечное хранение документов без права их уничтожения (ГОСТ Р 7.0.8-2013).

Значительная часть терминов этой группы называет понятия, связанные с технологиями документирования. Например:

кинодокумент: Изобразительный или аудиовизуальный документ, созданный кинематографическим способом (ГОСТ Р 51141-98);

кинодокумент: Изобразительный или аудиовизуальный документ, созданный фотографическим или электронным (цифровым) способом, фик- 
сирующий информацию в виде последовательно расположенных изображений - динамичных образов (ГОСТ Р 7.0.8-2013).

\section{4. Термины, которых не было в ГОСТ} P 51141-98, которые введены в ГОСТ Р 7.0.8-2013 и составляют новую часть терминосистемы.

Включение в стандарт таких терминов обусловлено разными причинами.

1. Повышение уровня организации работы с документами.

Это обусловило появление нового термина управление документами, отграничение его от предшествующих и связанных с ним единиц делопроизводство и документационное обеспечение (управления). Делопроизводство определяется как деятельность организации по созданию, обработке, использованию и оперативному хранению документов; документационное обеспечение (уnравления), ДОУ - как отрасль деятельности, обеспечивающая документирование и организацию работы с документами и документированной информацией в управлении; управление документами - как функция организации, заключающаяся в реализации единой политики и стандартов по отношению к документальному фонду организации на всех стадиях жизненного цикла документа.

2. Научное осмысление модернизации сферы делопроизводства и архивного дела, внедрение информационных технологий.

На сегодняшний день модернизация архивной отрасли является приоритетным вектором развития государственной политики, направленной на эффективную организацию предоставления информационных услуг пользователям (Распоряжение Правительства РФ № 2227-p). Вопросы модернизации делопроизводства и архивной отрасли получили освещение в специальной литературе, где используются обозначающие их термины. Так, исследователями сформулированы и обоснованы современные цели и задачи автоматизации архивного дела, охарактеризованы объекты автоматизации работы архива, рассмотрены вопросы создания информационнопоисковых систем архива, организации внедрения информационных технологий в архиве (см., например: [Алексеева и др., 2003; Куз- нецов, 2010]). И.Н. Киселевым представлен проект развития отечественной архивной сферы в условиях внедрения автоматизированных архивных технологий, показаны преимущества, которые будут иметь отечественные архивы и архивное дело в результате применения информационных технологий [Киселев, 2002].

Задачами модернизации являются: обеспечение доступности предоставления архивных информационных услуг посредством внедрения и широкого применения новых информационно-коммуникационных технологий, а также совершенствования законодательной и научно-методической базы архивного дела в новых условиях; обеспечение сохранности архивных ресурсов; оптимизация комплектования архивов; развитие информационного потенциала Архивного фонда РФ. Выполнение этих задач станет условием функционирования архивной отрасли на новом уровне, соответствующем динамике инновационного развития. Это позволит наиболее эффективно использовать архивные документы для удовлетворения потребностей граждан, информационного обеспечения деятельности органов государственной власти, образовательных и научных учреждений, общественных организаций [Косова, Топаз, 2018].

В ГОСТ Р 7.0.8-2013 вошли термины, которые появились в научных текстах и уже начали использоваться на практике. Например:

аутентичность (электронного документа): Свойство электронного документа, гарантирующее, что электронный документ идентичен заявленному;

пригодность для использования (электронного документа): Свойство электронного документа, позволяющее его локализовать и воспроизвести в любой момент времени;

электронная подпись: Информация в электронной форме, присоединенная к электронному документу или иным образом связанная с ним и позволяющая идентифицировать лицо, подписавшее электронный документ;

электронный документооборот: Документооборот с использованием автоматизированной информационной системы (системы электронного документооборота).

3. Методическое осмысление практического опыта.

Например, в методической литературе используется термин фонд личного проис- 


\section{МАТЕРИАЛЫ И СООБЩЕНИЯ}

хождения (Методические рекомендации), выделяются разновидности фондов личного происхождения, обосновывается практическая целесообразность разграничения таких комплексов, как коллекиия, собрание, персональное собрание. ГОСТ Р 7.0.8-2013 содержит термин, применяемый к документам личного происхождения:

архивный фонд личного происхождения: Архивный фонд, состоящий из документов, образовавшихся в процессе жизни и деятельности физического лица, семьи, рода.

4. Учет зарубежного опыта, нашедшего отражение в зарубежных источниках, в частности в международных стандартах.

Использование общероссийских и международных стандартов открывает российским архивам возможность быть включенными в международное информационное пространство. Это обусловливает применение на практике заимствованных терминов и включение их в российские стандарты, что способствует устранению барьеров в международной коммуникации, содействию научно-техническому прогрессу и сотрудничеству в различных областях.

Так, из стандарта ГОСТ Р ИСО 15489-12007 «СИБИД. Управление документами. Общие требования» перенесен в ГОСТ Р 7.0.8-2013 ряд терминов, например: конвертирование, метаданные, управление документами.

\section{Выводы}

Таким образом, стандарт на термины и определения является особым видом регламентирующего документа, лексикографического источника, который фиксирует форму и содержание терминов, упорядочивает систему понятий, обеспечивает единство подходов к толкованию терминов специалистами, тем самым способствуя успешной деловой профессиональной коммуникации. Он должен полно и точно отражать понятийный аппарат определенной профессиональной сферы.

Сопоставительный анализ действующего терминологического стандарта в сфере делопроизводства и архивного дела (ГОСТ P 7.0.8-2013) и предшествующего ему документа (ГОСТ Р 51141-98) позволил показать динамику понятийно-терминологического аппарата, установить факторы, которые обусловили изменение содержания терминов и появление новых единиц.

Полученные сведения о закономерностях изменения системы понятий и обозначающих их терминах не только позволят определить направления и способы оптимизации профессиональной коммуникации, но и дополнят имеющиеся в лингвистике представления о термине как единице языка, об особенностях использования терминов в документном тексте.

\section{СПИСОК ЛИТЕРАТУРЫ}

Алексеева Е. В., Афанасьева Л. П., Бурова Е. М., Осичкина Г. А., 2003. Архивоведческие аспекты в делопроизводстве: внедрение информационных технологий в работу архива // Секретарское дело. № 11. С. 59-64.

Белый В. В., 1982. Структурная и семантическая характеристика терминов в современном русском языке : автореф. дис. ... канд. филол. наук. М. 23 c.

Гринев-Гриневич С. В., 2008. Терминоведение. М. : Академия. 302 c.

Касавин И. Т., 2009. Энциклопедия эпистемологии и философии науки. М. : Канон+ : Реабилитация. $1248 \mathrm{c}$.

Киселев И. Н., 2002. Информационное общество и архивы России // Изменяющаяся Россия и российские архивы на рубеже веков : материалы конф. (г. Москва, 1-2 марта 2001 г.) / сост.: И. Н. Киселев, Ю. И. Садчиков. М. : Изд. центр РОИА. С. 107-114.

Косова М. В., Топаз А. И., 2018. Терминология архивной отрасли в условиях модернизации документационных процессов // Четвертые Моисеевские чтения : национальные и региональные особенности языка : материалы Bcepoc. (с междунар. участием) науч. конф. (г. Оренбург, 22-24 нояб. 2018 г.) / сост. и науч. ред. П. А. Якимов. Оренбург : Оренбург. кн. C. $154-157$.

Кузнецов С. Л., 2010. «Электронное правительство» и организация межведомственного электронного документооборота // Делопроизводство. № 3. C. 29-33.

Лемов А. В., 2000. Система, структура и функционирование научного термина (на материале русской лингвистической терминологии). Саранск : Изд-во Мордов. ун-та. 359 с.

Топаз А. И., 2017. Внедрение информационно-коммуникационных технологий в архивную от- 
расль Калининградской области: основные задачи // Документ как текст культуры : сб. науч. тр. Тула : Тул. произв. полигр. об-ние. Вып. 9. С. 62-65.

Янковая В. Ф., 2014. Новый ГОСТ Р 7.0.8-2013 взамен ГОСТ Р 51141-98 // Секретарь-референт. № 3. URL: https://www.profiz.ru/sr/3_2014/ (дата обращения: 18.03.2019).

\section{ИСТОЧНИКИ}

ГОСТ Р 51141-98 -ГОСТ Р 51141-98. Делопроизводство и архивное дело. Термины и определения. Введ. 1999-01-01. М. : Изд-во стандартов, $1998.8 \mathrm{c}$.

ГОСТ 1.1-2002 - ГОСТ 1.1-2002. Межгосударственная система стандартизации. Термины и определения. Введ. 2003-07-01. М. : Изд-во стандартов, $2003.30 \mathrm{c}$.

ГОСТ Р ИСО 15489-1-2007 - Национальный стандарт РФ ГОСТ Р ИСО 15489-1-2007. СИБИД. Управление документами. Общие требования. Введ. 2007-07-01. М. : Стандартинформ, $2007.34 \mathrm{c}$.

ГОСТ Р 7.0.8-2013 - Национальный стандарт РФ ГОСТ Р 7.0.8-2013. СИБИД. Делопроизводство и архивное дело. Термины и определения. Взамен ГОСТ Р 51141-98. Введ. 2014-03-01. М. : Стандартинформ, 2014. 26 с.

Методические рекомендаџии - Методические рекомендации по работе с документами личного происхождения (литература и искусство). М. : ЦГАЛИ, 1990. 255 с.

Распоряжение Правительства РФ№ 2227-р-Распоряжение Правительства РФ от 08.12.2011 № 2227-р «О Стратегии инновационного развития РФ на период до 2020 года». Доступ из справ.-правовой системы «КонсультантПлюс».

Федеральный закон № 125-Ф3 - Федеральный закон от 22.10.2004 № 125-Ф3 «Об архивном деле в Российской Федерации» (ред. от 13.05.2008) // Собрание законодательства РФ. 2004. 25 окт. (№ 43). Ст. 4169.

Федеральный закон № 162-Ф3 - Федеральный закон от 29.06.2015 № 162-Ф3 «О стандартизации в Российской Федерации» // Собрание законодательства РФ. 2015. 6 июля (№ 27). Ст. 3953.

\section{REFERENCES}

Alekseeva E.V., Afanasyeva L.P., Burova E.M., Osichkina G.A., 2003. Arkhivovedcheskie aspekty $\mathrm{v}$ deloproizvodstve: vnedrenie informatsionnykh tekhnologiy v rabotu arkhiva [Archival Aspects in Clerical Work: The Introduction of Information Technologies in the Work of the Archive]. Sekretarskoe delo, no. 11, pp. 59-64.

Belyy V.V., 1982. Strukturnaya i semanticheskaya kharakteristika terminov $v$ sovremennom russkom yazyke: avtoref. dis. ... kand. filol. nauk [Structural and Semantic Characteristics of Terms in the Modern Russian Language. Cand. philol. sci. abs. diss.]. Moscow. 23 p.

Grinev-Grinevich S.V., 2008. Terminovedenie [Terminology Studies]. Moscow, Academiya Publ. 302 p.

Kasavin I.T., 2009. Entsiklopediya epistemologii $i$ filosofii nauki [Encyclopedia of Epistemology and Philosophy of Science]. Moscow, Kanon+ Publ., Reabilitatsiya Publ. 1248 p.

Kiselev I.N., 2002. Informatsionnoe obshchestvo i arkhivy Rossii [Information Society and Archives of Russia]. Kiselev I.N., Sadchikov Yu.I., eds. Izmenyayushchayasya Rossiya i rossiyskie arkhivy na rubezhe vekov: materialy konf. (g. Moskva, 1-2 marta 2001 g.) [Changing Russia and Russian Archives at the Turn of the Century. Proceedings of the Conference (Moscow, March 1-2, 2001)]. Moscow, Izdatelskiy tsentr ROIA, pp. 107-114.

Kosova M.V., Topaz A.I., 2018. Terminologiya arkhivnoy otrasli $\mathrm{v}$ usloviyakh modernizatsii dokumentatsionnykh protsessov [Terminology of the Archival Industry in the Context of Modernization of Documentation Processes]. Yakimov P.A., ed. Chetvertye Moiseevskie chteniya: natsionalnye $i$ regionalnye osobennosti yazyka: materialy Vseros. (s mezhdunar. uchastiem) nauch. konf. (g. Orenburg, 22-24 noyab. 2018 g.) [Fourth Moiseev Readings: National and Regional Features of the Language. Proceedings of the All-Russian (With International Participance) Scientific Conference (Orenburg, November 2224, 2018)]. Orenburg, Orenburg. kn., pp. 154-157.

Kuznetsov S.L., 2010. «Elektronnoe pravitelstvo» i organizatsiya mezhvedomstvennogo elektronnogo dokumentooborota ["Electronic Government" and the Organization of Interdepartmental Electronic Document Management]. Deloproizvodstvo, no. 3, pp. 29-33.

Lemov A.V., 2000. Sistema, struktura $i$ funktsionirovanie nauchnogo termina (na materiale russkoy lingvisticheskoy terminologii) [System, Structure and Functioning of a Scientific Term (On the Material 
of Russian Linguistic Terminology)]. Saransk, Izd-vo Mordovskogo universiteta. 359 p.

Topaz A.I., 2017. Vnedrenie informatsionnokommunikatsionnykh tekhnologiy v arkhivnuyu otrasl Kaliningradskoy oblasti: osnovnye zadachi [Implementation of Information and Communication Technologies in the Archival Industry of Kaliningrad Region: The Main Tasks]. Dokument kak tekst kultury: sb. nauch. tr. [Document as a Text of Culture. Collection of Scientific Works]. Tula, Tulskoe proizvodstvennoe poligrafskoe obyedinenie, iss. 9, pp. 62-65.

Yankovaya V.F., 2014. Novyy GOST R 7.0.8-2013 vZamen GOST R 51141-98 [New GOST R 7.0.82013 Instead of GOST R 51141-98]. Sekretarreferent, no. 3. URL: https://www.profiz.ru/sr/ 3_2014/(accessed 18 March 2019).

\section{SOURCES}

GOST R 51141-98. Deloproizvodstvo $i$ arkhivnoe delo. Terminy i opredeleniya. Vved. 1999-0101. [GOST P 51141-98. Records Management and Archive Keeping. Terms and Definitions. Introduced January 1, 1999]. Moscow, Izd-vo standartov, $1998.8 \mathrm{p}$.

GOST 1.1-2002. Mezhgosudarstvennaya sistema standartizatsii. Terminy i opredeleniya. Vved. 2003-07-01 [GOST 1.1-2002. Interstate Standardization System. Terms and Definitions. Introduced July 1, 2003]. Moscow, Izd-vo standartov, 2003. $30 \mathrm{p}$.

Natsionalnyy standart RF GOST R ISO 15489-12007. SIBID. Upravlenie dokumentami. Obshchie trebovaniya. Vved. 2007-07-01 [The National Standard of the Russian Federation GOST Р ИСО 15489-1-2007. The System of Standards for Information, Librarianship and Publishing. Document Management. General
Requirements. Introduced July 1, 2007].

Moscow, Standartinform, 2007. 34 p.

Natsionalnyy standart RF GOST R 7.0.8-2013. SIBID. Deloproizvodstvo $i$ arkhivnoe delo. Terminy $i$ opredeleniya. Vzamen GOST R 51141-98. Vved. 2014-03-01 [The National Standard of the Russian Federation GOST P 7.0.8-2013. System of Standards for Information, Librarianship and Publishing. Records Management and Archive Keeping. Terms and Definitions. Instead of GOST P 51141-98. Introduced March 1, 2014]. Moscow, Standartinform, 2014. $26 \mathrm{p}$.

Metodicheskie rekomendatsii po rabote $s$ dokumentami lichnogo proiskhozhdeniya (literatura i iskusstvo) [Guidelines for Working with Documents of Personal Origin (Literature and Art)]. Moscow, TSGALI, 1990. 255 p.

Rasporyazhenie Pravitelstva RF ot 08.12.2011 № 2227-r «O Strategii innovatsionnogo razvitiya $R F$ na period do 2020 goda» [Order of the Government of the Russian Federation of December 8, 2011 no. 2227-p "On the Strategy of Innovative Development of the Russian Federation for the Period Untill 2020"]. Access from Reference Legal System "KonsultantPlus".

Federalnyy zakon ot 22.10.2004 № 125-FZ «Ob arkhivnom dele v Rossiyskoy Federatsii» (red. ot 13.05.2008) [Federal Law of October 22, 2004 no. 125-FZ "On Archival Affairs in the Russian Federation" (as Amended on May 13, 2008)]. Sobranie zakonodatelstva RF [Collection of Legislation of the Russian Federation], 2004, October 25 (no. 43), art. 4169.

Federalnyy zakon ot 29.06.2015 № 162-FZ «O standartizatsii v Rossiyskoy Federatsii» [Federal Law of June 29, 2015 no. 162-FZ “On Standardization in the Russian Federation"]. Sobranie zakonodatelstva RF [Collection of Legislation of the Russian Federation], 2015, July 6 (no. 27) artl. 3953.

\section{Information about the Author}

Alina I. Topaz, Postgraduate Student, Department of Russian Philology and Journalism, Volgograd State University, Prosp. Universitetsky, 100, 400062 Volgograd, Russia, alina-topaz@yandex.ru, https://orcid.org/0000-0002-9230-2684

\section{Информация об авторе}

Алина Игоревна Топаз, аспирант кафедры русской филологии и журналистики, Волгоградский государственный университет, просп. Университетский, 100, 400062 г. Волгоград, Россия, alina-topaz@yandex.ru,https://orcid.org/0000-0002-9230-2684 